\title{
Transbrachial approach as the first alternative to transradial approach for coronary angiography
}

\author{
(iDLara Gudelj" ${ }^{*}$, \\ (D)Matias Trbušićci,2
}

'University of Zagreb School of Medicine, Zagreb, Croatia

${ }^{2}$ University Hospital Centre

"Sestre milosrdnice", Zagreb, Croatia
RECEIVED:

December 5, 2020

ACCEPTED:

December 18, 2020

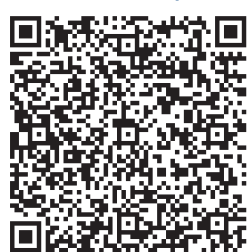

KEYWORDS: trans-brachial approach, coronary angiography, trans-femoral approach, trans-radial approach.

CITATION: Cardiol Croat. 2021;16(1-2):40. | https://doi.org/10.15836/ccar2021.40

*ADDRESS FOR CORRESPONDENCE: Lara Gudelj, Medicinski fakultet, Šalata 2, HR-10000 Zagreb, Croatia. / Phone: +385-98-407266 / E-mail: gudelj.lara@gmail.com

ORCID: Lara Gudelj, https://orcid.org/0000-0002-4049-7723• Matias Trbušić, https://orcid.org/0000-0001-9428-454X

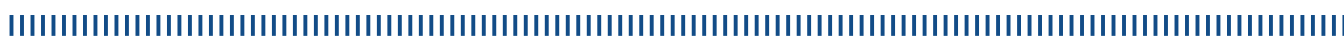

Introduction: Transradial access (TRA) is well established approach but there is a possibility of a failure due to anatomic vascular anomalies, radial artery spasm or stenosis. Secondary approach is needed, and most clinicians tend to use transfemoral access (TFA). Some believe that transbrachial approach (TBA) is an obsolete catheterization route due to high risk of complications..$^{1-3}$ Our hypothesis is that for TR cardiologists with high success rate, TBA is easier and more suitable first alternative. In TRA era complications of TFA are relatively more common because trainees have no experience in femoral artery compression nor staff with care around puncture site. We have decided to investigate outcomes of TBA for coronary angiography and intervention. The aim of this study was to demonstrate effectiveness and feasibility of TBA for percutaneous coronary intervention in patients in whom TRA is not possible.

Patients and Methods: We collected all cases that underwent diagnostic coronary angiography and intervention from August 2012 to February 2020, with total of 116 patient. Arterial sheath was removed 6 hours (hrs) after procedure if coronary intervention was performed or 3 hrs after coronary angiography. Direct manual pressure was applied to brachial artery for $10 \mathrm{~min}$, after hemostasis was secured, further local pressure with elastic bandages for 2 hrs. Patients were advised to restrict movements of hand, especially elbow and best rest for 6 hrs.

Results: Median patient age of patients was 69 yrs., with 70 male patients (63\%). There was only 1 case of major complications of arterial thrombosis due to intensive elastic bandage compression and $1 \mathrm{mi}-$ nor complication of hematoma that resolved in few weeks. Our low complication rate could be since we used material intended for radial artery puncture and accurate puncture technique was performed with gentle, delicate maneuver of catheter. Since $\mathrm{P}<0.05$ we consider these results statistically significant.

Conclusion: Results we have presented show that TBA is effective and feasible alternative to TRA with many advantages in comparison to TFA such as early ambulation, positive feedback from patients and availability in aortoiliac disease if performed by operators experienced in arm approaches. However, more caution is needed that with TRA to avoid complications such as thrombosis.

1. Kiemeneij F, Laarman GJ, Odekerken D, Slagboom T, van der Wieken R. A randomized comparison of percutaneous transluminal coronary angioplasty by the radial, brachial and femoral approaches: the access study. J Am Coll Cardiol. 1997 May;29(6):1269-75. https://doi.org/10.1016/S0735-1097(97)00064-8

2. Gan HW, Yip HK, Wu CJ. Brachial approach for coronary angiography and intervention: totally obsolete, or a feasible alternative when radial access is not possible? Ann Acad Med Singap. 2010 May;39(5):368-73. PubMed: https://pubmed.ncbi.nlm.nih.gov/20535426/

3. Lam UP, Lopes Lao EP, Lam KC, Evora M, Wu NQ. Trans-brachial artery access for coronary artery procedures is feasible and safe: data from a single-center in Macau. Chin Med J (Engl). 2019 Jun 20;132(12):1478-1481. https://doi.org/10.1097/CM9.0000000000000274 